\title{
Quality of care and health status in Ukraine
}

\author{
John W Peabody ${ }^{1,2^{*}}$, Jeff Luck ${ }^{3}$, Lisa DeMaria ${ }^{1}$ and Rekha Menon ${ }^{4}$
}

\begin{abstract}
Background: We conducted a national level assessment of the quality of clinical care practice in the Ukrainian healthcare system for two important causes of death and chronic disease conditions. We tested two hypotheses: a) quality of care is predicted by physician and facility characteristics and b) health status is predicted by quality of care.

Methods: During 2009-2010 in Ukraine, we collected nationally-representative data from clinical facilities, physicians, Clinical Performance and Value (CPV $\left.{ }^{\circledR}\right)$ vignettes, patient surveys from the facilities, and from the general population. Each physician completed a written CPV ${ }^{\otimes}$ vignette - a simulated case scenario of a typical patient visit_-for each of two clinical cases, congestive heart failure (CHF) and chronic obstructive pulmonary disease (COPD). CPV ${ }^{\otimes}$ vignette scores, calculated as a percentage of all care criteria completed by the physician, were used as the measure of clinical quality of care. Self-reported health measures were collected from exit and household survey respondents. Regression models were developed to test the two study hypotheses.

Results: 136 hospitals and 125 polyclinics were surveyed; 1,044 physicians were interviewed and completed CPV ${ }^{\circledR}$ vignettes. On average physicians scored $47.4 \%$ on the vignettes. Younger, female physicians provide a higher quality of care-as well as those that have had recent continuing medical education (CME) in chronic disease or health behaviors. Higher quality was associated with better health outcomes.

Conclusions: As low- and middle-income countries around the world are challenged by non-communicable diseases, higher quality of care provided to these populations may result in better outcomes, such as improved health status and life expectancy, and overcome regional shortfalls. Policy efforts that serially evaluate quality may improve chronic disease care.
\end{abstract}

Keywords: Quality of care, Health care delivery, Non-communicable diseases, Health policy, Ukraine, Eastern Europe

\section{Background}

In most countries today, whether rich or poor, a growing burden of non-communicable diseases (NCDs) is a significant policy issue. The high prevalence and resulting burden of chronic diseases pose challenges to health care systems to adequately diagnose and treat individual patients.

Over the past 20 years, Ukraine has been undergoing a health crisis [1]. Life expectancy is increasing gradually following a sharp drop after independence [2], but remains below most other European countries, at 68 years compared to 79 for Europe as a whole; worse still, 13\% of these years (7.7 years in total) are spent in poor health [3]. NCDs already account for a staggering $82 \%$ of all

\footnotetext{
* Correspondence: jpeabody@qurehealthcare.com

${ }^{1}$ QURE Healthcare, 1000 Fourth Street, Ste 300, San Rafael, CA 94901, USA

${ }^{2}$ University of California, 50 Beale Street, 12th Floor, San Francisco, CA 94105, USA

Full list of author information is available at the end of the article
}

deaths in the country and are especially preventable or treatable [3]. The most common NCDs-coronary heart disease (CHD), congestive heart failure (CHF), and chronic obstructive pulmonary disease (COPD), along with hypertension and diabetes-are major contributors to the declining life expectancy in Ukraine and other post-Soviet countries [4].

The impact of NCDs on health outcomes and perceptions of inadequate care in many low and middleincome countries (LMICs) have heightened interest in the quality of clinical care, particularly for diagnosing and treating cardiovascular (CVD) [5] and chronic respiratory disease (CRD). Better diagnosis and treatment, particularly of associated risk factors, has led to improved CVD and, to a lesser extent CRD, outcomes in more developed economies [5].

Thus there is an underlying urgency to understand how the quality of clinical care can be measured at a population level in LMICs [6-8]. Recent research from 
developed and developing countries shows that quality can be measured at the community level. Extending this work to a national level assessment of the quality of care for NCDs, might make it possible to relate quality of care to health status at the patient or even the community level [9].

We conducted a national study of the quality of care in Ukraine, a middle-income country where, despite some incremental reforms in the past two decades [10], there is a pressing need for improved health system effectiveness [11]. Most care is delivered by employed physicians in government-operated facilities, including polyclinics and hospital outpatient clinics. Although the tax-financed system is nominally free at the point of care, it faces challenges of underinvestment and widespread informal payments [12].

We used two practical, affordable measurement tools to evaluate the quality of care for, and health impacts of, NCDs on a population scale. The first is measurement using simulated cases. Physicians and other providers care for patients as they would an actual patient, to demonstrate and benchmark how their care compares to evidence-based practice [13,14]. Clinical Performance and Value $\left(\mathrm{CPV}^{\oplus}\right)$ vignettes, simulations that have been used widely in different countries and practice settings, are affordable $[15,16]$ and have been validated against actual clinical practice $[13,14]$. Moreover, improvements in CPV scores have been experimentally linked to better patient outcomes. The second advance is the increasing reliance on self-reported health status measures as a measure of health status in population studies [17-19]. A series of studies have established that General SelfReported Health (GSRH) status is a robust predictor of overall health status and a predictor of future health expenditures, and is related to clinical practice [20,21].

We conducted a national level assessment of the quality of care in the Ukraine healthcare system to for COPD and CHF, two of the most important causes of NCD burden and mortality. We tested two hypotheses: 1) quality of care for NCDs can be predicted by physician and facility characteristics that are amenable to policy interventions and 2) the quality of care as measured by CPVs predicts health status of individuals using the facilities and the population as a whole.

\section{Methods}

Data for this study were derived from a coordinated series of surveys conducted in Ukraine during 2009 and 2010. We collected data from clinical facilities, physicians, $\mathrm{CPV}^{\ominus}$ vignettes for COPD and CHF, patient surveys at the facilities, and a household survey of the general population. The 2009 household survey collected data from over 3,000 adults in 1,408 households. In 2010, data were collected at over 250 health care facilities that served residents of geographic areas sampled in the household survey.

\section{Sampling and data collection Household survey}

The household survey was the foundation for a sampling strategy designed to link population and patient health data with structural and quality measures of the health care delivery system. The household survey collected data in 8 of 27 oblasts, (equivalent of a state or province) including the capital city of Kiev and the Autonomous Republic of Crimea. These oblasts were selected to be representative of 4 major regions of Ukraine-West, North/Center, East, and South-and are home to approximately $18 \mathrm{M}$ of the country's 46 million residents. In each oblast (except urban Kiev), 22 enumeration areas (EAs) were randomly selected, equally divided between rural and urban areas. Neighborhoods were then randomly selected within each EA, and households randomly selected within neighborhoods. All adults in each selected household were interviewed [1].

\section{Facility survey and structural quality of care measures}

Next we sampled facilities that served residents of the household survey EAs. Each polyclinic serving one or more EAs was identified and designated as either urban serving or rural-serving based on the EAs it served. Polyclinics were then randomly selected to cover as many EAs as possible (given budget constraints) and achieve a distribution of polyclinics comparable to the national urban:rural population ratio. The rayon or city hospital to which each sampled polyclinic referred patients was then selected; its urban or rural designation matched that of the referring polyclinic(s). The oblast hospital in each oblast was also included and was designated as urban-serving.

A total of 136 hospitals and 125 polyclinics were surveyed (Table 1). On average, facilities were more than 20 years old. The facilities served large populations with substantial inpatient (bed) capacity and had long operating hours, such as polyclinics that were open an average of 58.7 and 72.7 hours a week for emergency care. Each facility was staffed by a large number of providers (averaging 180, 78 and 43 doctors at oblast hospitals, rayon hospitals and polyclinics, respectively) seeing many outpatients a month. Polyclinics averaged 20,013 outpatient visits a month, while oblast and rayon hospitals averaged 14,631 and 13,259 , respectively. A large fraction of patient volume was for older patients, presumably patients more likely to have chronic or even multiple conditions.

Data on structural quality included human, material and financial resources as well as services and productivity data. We constructed three indices-based on lists used successfully in facility surveys in other countries and 
Table 1 Facility characteristics, by facility type

\begin{tabular}{|c|c|c|c|c|}
\hline & $\begin{array}{l}\text { All facility types } \\
N=261\end{array}$ & $\begin{array}{l}\text { Oblast hospital } \\
\mathrm{N}=8\end{array}$ & $\begin{array}{l}\text { Rayon/Town hospital } \\
\mathrm{N}=128\end{array}$ & $\begin{array}{l}\text { Polyclinic } \\
\mathrm{N}=125\end{array}$ \\
\hline \multicolumn{5}{|l|}{ General Facility Information } \\
\hline \multirow[t]{2}{*}{ Age of facility } & 25.5 & 51.3 & 28 & 21.1 \\
\hline & {$[29.4]$} & {$[73.02]$} & {$[32.1]$} & {$[19.4]$} \\
\hline \multirow[t]{2}{*}{ Population served } & $129,589.7$ & $2,418,672$ & $132,326.3$ & $52,567.2$ \\
\hline & {$[431,184.6]$} & {$[1,197,941]$} & {$[397,339.5]$} & {$[83,040.9]$} \\
\hline \multirow[t]{2}{*}{ Number of licensed beds/facility (hospitals) } & 332.6 & 894 & 296.7 & \\
\hline & {$[252.9]$} & {$[326.3]$} & {$[201.2]$} & \\
\hline \multirow[t]{2}{*}{ Number of beds in use/facility (hospitals) } & 302.1 & 892.4 & 263.1 & \\
\hline & {$[239.6]$} & {$[328.9]$} & [173.7] & \\
\hline \multirow[t]{2}{*}{ Number of listed committees or bodies in place } & 3.1 & 4.3 & 3.5 & 2.7 \\
\hline & {$[1.7]$} & {$[1.5]$} & {$[1.7]$} & {$[1.6]$} \\
\hline \multicolumn{5}{|l|}{ Clinical Hours } \\
\hline \multirow[t]{2}{*}{ Total hours open (Monday-Sunday) } & 100.1 & 152.5 & 138.5 & 58.7 \\
\hline & {$[53.9]$} & {$[43.9]$} & {$[49.3]$} & {$[9.8]$} \\
\hline \multirow[t]{3}{*}{ Total hours for emergencies } & 132.8 & 168 & 165.8 & 72.7 \\
\hline & [51.1] & {$[0.0]$} & [12.01] & {$[38.8]$} \\
\hline & All facility types & Oblast hospital & Rayon/Town hospital & Polyclinic \\
\hline \multicolumn{5}{|l|}{ Patient load } \\
\hline \multirow[t]{2}{*}{ Total number of doctors } & 64.5 & 179.6 & 78.02 & 42.8 \\
\hline & {$[64.4]$} & {$[122.4]$} & {$[69.5]$} & {$[36.1]$} \\
\hline \multirow{2}{*}{$\begin{array}{l}\text { Number of nurses, other clinical staff } \\
\text { (e.g. medical technicians, pharmacists) }\end{array}$} & 195.5 & 681.9 & 262.2 & 90.6 \\
\hline & {$[202.4]$} & {$[446.2]$} & {$[186.9]$} & {$[75.3]$} \\
\hline \multirow[t]{2}{*}{ Number of OP visits/month } & $17,587.1$ & $13,259.2$ & $14,631.2$ & $20,013.4$ \\
\hline & {$[16,794.5]$} & {$[8,440.3]$} & {$[15,978.1]$} & {$[17,339.5]$} \\
\hline \multirow[t]{2}{*}{ Number of inpatient admissions/month (hospitals only) } & $1,058.8$ & $4,624.3$ & 857.5 & \\
\hline & {$[1,268.95]$} & {$[3,241.5]$} & [651.92] & \\
\hline \multirow[t]{2}{*}{$\%$ adult patients $(>18)$} & 73.8 & 61.5 & 71.9 & 76.4 \\
\hline & {$[30.1]$} & [36.9] & {$[31.1]$} & {$[28.7]$} \\
\hline \multirow[t]{3}{*}{$\%$ of adult patients $>65$} & 21.2 & 16.3 & 19.5 & 23.2 \\
\hline & {$[15.4]$} & {$[9.6]$} & [13.04] & {$[17.6]$} \\
\hline & All facility types & Oblast hospital & Rayon/Town hospital & Polyclinic \\
\hline \multicolumn{5}{|l|}{ Facility Equipment/Supplies } \\
\hline \multirow[t]{2}{*}{$\%$ of equipment in good working condition (out of 16 items) } & 46.0 & 80 & 55.7 & 34.7 \\
\hline & {$[18.2]$} & {$[10.1]$} & {$[15.3]$} & {$[12.9]$} \\
\hline \multirow[t]{2}{*}{$\%$ of tests performed (out of 15 items) } & 76.9 & 92.2 & 79.7 & 73.0 \\
\hline & {$[19.1]$} & {$[9.9]$} & {$[15.3]$} & {$[21.97]$} \\
\hline \multirow[t]{2}{*}{$\%$ of supplies available (out of 12 items) } & 74.8 & 85.4 & 79.2 & 69.6 \\
\hline & {$[18.1]$} & {$[19.3]$} & {$[15.8]$} & {$[18.8]$} \\
\hline \multirow[t]{2}{*}{ Annual Expenses/facility* } & $\$ 2,220,828$ & $\$ 6,411,543$ & $\$ 2,208,281$ & $\$ 724,702$ \\
\hline & {$[49,600,000]$} & {$[21,400,000]$} & {$[65,100,000]$} & {$[6,789,152]$} \\
\hline
\end{tabular}

*Average 2009 exchange rate of 7.97hryvna = USD\$1. http://www.tradingeconomics.com/ukraine/currency. 
reviewed for appropriateness in the Ukrainian context-to quantify the availability of materials needed to provide basic outpatient and inpatient health care: the availability of medical equipment in good working condition; laboratory tests available at the facility; and the availability of basic clinical supplies (Table 1). Each possible equipment item, laboratory test, or supply item was recorded as available or not, and indices present the proportion of items available.

In general, hospitals had higher values of the structural quality indices than did polyclinics. However, there was significant variation in the working order of equipment across facilities (on average, $56 \%$ at hospitals and 35\% at polyclinics), the percentage of tests performed and the adequacy of supplies across and within facilities of the same type (See Table 1).

\section{Physician survey and clinical quality of care measures}

We then randomly sampled eligible physicians within each sampled facility. Eligible physicians were those with training in primary care (internal medicine, family medicine, general practice, or social medicine) or relevant specialties (pulmonology/TB for the COPD case or cardiology for the CHF case). At each site, eligible physicians were rostered and four were randomly selected and invited to participate. Of physicians who were approached, 61\% agreed to complete the physician survey and $\mathrm{CPV}^{-}$ vignettes. Of physicians who refused, 93\% cited questionnaire length or lack of time as reasons; $6 \%$ cited reluctance to provide confidential information.

The physician survey gathered information about training, current practice, patient load and socio-demographic and economic indicators. We surveyed a total of 1,044 physicians (Table 2). Three quarters were women, with an average age of 47 with 22 years of experience, roughly equally split between Ukrainian speaking and Russian speaking; 1 in 6 to 7 worked at another facility. There were more primary care physicians and numbers of patients seen per month in polyclinics than hospitals, although roughly all facilities had the same proportion of patients over 40 .

Each physician also completed 2 Clinical Performance and Value ${ }^{\oplus}\left(\mathrm{CPV}^{\bullet}\right)$ vignettes, which measured quality of clinical care. A $\mathrm{CPV}^{\ominus}$ vignette is a written case simulation of a typical visit from a patient with a given condition. Physicians are asked to take a history, describe the physical examination, order tests, make a diagnosis, and prescribe treatment as they would in an actual practice setting. $\mathrm{CPV}^{\oplus}$ vignettes have been validated against actual physician practice in prospective randomized trials in developed country settings [13,14] and produce comparable results in developing countries [16]. They are capable of detecting changes in physician behavior and quality of care across time [22]. Most recently improvements in
$\mathrm{CPV}^{\curvearrowleft}$ vignette scores have been experimentally linked to improved health status, strongly linking health outcomes to actual clinical practice in LMICs.

For this study, $\mathrm{CPV}^{\oplus}$ vignettes were developed for COPD and CHF. These two NCDs are strongly associated with an aging population and carry a high burden of disease. $\mathrm{CHF}$, the end stage of many cardiac conditions, accounts for $38.4 \%$ of all deaths in Ukraine [4]; COPD is the third leading cause of death and accounts for $2.9 \%$ of all deaths, although this is almost certainly under-reported [4]. A simple and a complex $\mathrm{CPV}^{\otimes}$ vignette were developed for each disease.

Physicians were randomly assigned one complex and one simple $\mathrm{CPV}^{\oplus}$ vignette case across the two diseases. Completed $\mathrm{CPV}^{\oplus}$ vignettes were translated from Ukrainian or Russian into English and then scored by trained physician abstractors, using a predefined set of criteria of care for each $\mathrm{CPV}^{\ominus}$ vignette. Physician abstractors have specialty training appropriate for the $\mathrm{CPV}^{\bullet}$ vignette cases, and a sample of the $\mathrm{CPV}^{\circledR}$ vignettes were over-read by the lead author to ensure accuracy. Scoring criteria were based on US and international standards of care for the two diseases $[23,24]$ and reviewed by an expert panel of Ukrainian physicians. For each $\mathrm{CPV}^{\bullet}$ vignette, scores were calculated as the percentage of items (40-55 criteria for each case) "done" correctly. A total percent score was calculated along with scores for each of five major domains: history taking, physical exam, laboratory testing and imaging, diagnosis, and treatment and management. Historically, the highest $\mathrm{CPV}^{\oplus}$ scores range from $65-80 \%$, for very good to excellent care, while the range of scores for good to fair care is from $45-65 \%[9,16,22]$.

\section{Patient exit survey and health measures}

Finally, we sampled patients who were seen by physicians who completed CPVs. At a randomly selected subset of 100 polyclinics, patients who were seen by one of the study physicians on the day of the survey were sequentially invited to participate, until the target of 5 patients per study physician (a total of 20 exit surveys per facility) was complete.

The patient exit survey contained the same general self-reported health status (GSRH) measure used in the household survey. It employed a five point ordinal scale (translated as "Very good", "Good", "Satisfactory", "Bad" and "Very Bad") to describe health status. GSRH has been shown to predict objective measures of health, mortality and health care utilization [21,25]. Additional objective health measures were collected from household survey participants. These included height and weight (and the resulting body-mass index (BMI)), waist circumference, and blood pressure. 
Table 2 Physician characteristics and quality of care

\begin{tabular}{|c|c|c|c|c|c|}
\hline Characteristics & All facility types & All hospitals & $\begin{array}{l}\text { Oblast hospital } \\
(\mathrm{N}=34)\end{array}$ & $\begin{array}{l}\text { Rayon/Town hospital } \\
(\mathrm{N}=509)\end{array}$ & $\begin{array}{l}\text { Polyclinic } \\
(\mathrm{N}=500)\end{array}$ \\
\hline \multicolumn{6}{|l|}{ Social Demographics } \\
\hline Gender (male) \% & 24.7 & 35.2 & 35.3 & 28.3 & 20.4 \\
\hline \multirow[t]{2}{*}{ Age } & 47.3 & 47.5 & 45.4 & 47.6 & 47.2 \\
\hline & {$[11.1]$} & [11.1] & {$[13.2]$} & {$[10.9]$} & {$[11.1]$} \\
\hline \multicolumn{6}{|l|}{ Language spoken at home (\%): } \\
\hline Ukrainian & 43.4 & 42.9 & 45.2 & 42.8 & 44 \\
\hline Russian & 41.7 & 42.7 & 32.3 & 43.4 & 40.5 \\
\hline Both & 13 & 13.1 & 22.6 & 12.5 & 13 \\
\hline Other & 2 & 1.3 & 0 & 1.4 & 2.6 \\
\hline \multicolumn{6}{|l|}{ Medical Training } \\
\hline \multirow[t]{2}{*}{ Years practicing as physician } & 22.2 & 22.5 & 20.7 & 22.6 & 21.9 \\
\hline & {$[10.7]$} & 10.7 & [13] & {$[10.5]$} & {$[10.9]$} \\
\hline \multirow[t]{2}{*}{ Years practicing at the facility } & 17.6 & 17.7 & 14.1 & 17.9 & 17.4 \\
\hline & {$[10.5]$} & 10.4 & {$[10.1]$} & {$[10.4]$} & {$[10.7]$} \\
\hline \multicolumn{6}{|l|}{ Patient Load } \\
\hline General Practitioners (primary care) (\%) & 25.9 & 11.2 & 5.9 & 11.6 & 41.8 \\
\hline Patients $\geq \mathbf{4 0}$ years old (\%) & 58 & 57.2 & 54.8 & 59.5 & 56.6 \\
\hline \multirow[t]{2}{*}{ Hours/week at the facility } & 42.6 & 43.8 & 39.8 & 44.1 & 41.4 \\
\hline & [11] & 11.3 & {$[9.6]$} & {$[11.4]$} & {$[10.5]$} \\
\hline \multirow[t]{2}{*}{ Inpatients per month (number) } & 28.7 & 53.1 & 27.4 & 40.7 & 16.9 \\
\hline & [54] & 88.2 & {$[23.9]$} & {$[65.4]$} & {$[37.9]$} \\
\hline \multirow[t]{2}{*}{ Outpatients/month (number) } & 274.3 & 107.7 & 176.6 & 132.6 & 423.7 \\
\hline & {$[276.4]$} & 137.8 & {$[301]$} & {$[214]$} & [252] \\
\hline \multirow[t]{2}{*}{ Minutes per OP visit } & 36.6 & 51.0 & 52.7 & 51.3 & 27.2 \\
\hline & {$[53.7]$} & {$[72.57]$} & {$[74.7]$} & {$[72.6]$} & {$[33.5]$} \\
\hline Work in other facilities (\%) & 13.5 & 13 & 18.2 & 12.8 & 13.9 \\
\hline \multirow[t]{2}{*}{ Hrs/week at other facilities } & 20.1 & 21.4 & 11.8 & 22.2 & 18.7 \\
\hline & {$[16.1]$} & 16.3 & {$[6.1]$} & {$[16.6]$} & {$[16]$} \\
\hline \multicolumn{6}{|l|}{ Case Type } \\
\hline All COPD & $41.5 \pm 12.7$ & $41.9 \pm 12.5$ & $41.7 \pm 10.7$ & $41.9 \pm 12.6$ & $41.1 \pm 13.1$ \\
\hline All CHF & $53.2 \pm 13.1$ & $53.2 \pm 13.1$ & $57.3 \pm 11.6$ & $52.9 \pm 13.2$ & $53.2 \pm 13.0$ \\
\hline All Cases & $47.4 \pm 11.4$ & $47.5 \pm 11.1$ & $49.5 \pm 8.7$ & $47.4 \pm 11.3$ & $47.2 \pm 11.6$ \\
\hline \multicolumn{6}{|l|}{ By Domain (combined COPD + CHF) } \\
\hline History & $59.9 \pm 11.0$ & $59.8 \pm 10.9$ & $61.8 \pm 8.7$ & $59.6 \pm 11.0$ & $60.0 \pm 11.1$ \\
\hline Physical exam & $54.4 \pm 23.8$ & $55.6 \pm 23.0$ & $56.9 \pm 24.8$ & $55.5 \pm 22.9$ & $53.1 \pm 24.5$ \\
\hline Laboratory tests & $77.5 \pm 24.2$ & $78.0 \pm 23.9$ & $81.4 \pm 18.8$ & $77.7 \pm 24.2$ & $77.0 \pm 24.8$ \\
\hline Diagnosis & $56.0 \pm 14.6$ & $56.2 \pm 15.3$ & $58.8 \pm 14.1$ & $56.0 \pm 15.3$ & $55.8 \pm 13.8$ \\
\hline Treatment/Management & $40.9 \pm 12.9$ & $40.8 \pm 12.7$ & $42.1 \pm 12.1$ & $40.7 \pm 12.8$ & $41.0 \pm 13.2$ \\
\hline
\end{tabular}

We found that those individuals using the facilities (from the exit survey compared to the household survey) were more likely to be women, older, unmarried, Russian speaking, less educated and unemployed. They also lived further from the facilities and reported worse health status, were less likely to smoke, have more chronic conditions, and had three times as many hospitalizations in the past year. From the household survey, we observed heavy drinking rates $(17.6 \%$ having $\geq 5$ drinks one or more days in the past month) along with a sedentary 
lifestyle (71.6\%). One third to half were overweight, depending on the metric used (See Table 3).

All study instruments were translated into Russian and Ukrainian, back-translated to English, and piloted to ensure they were clear and understandable.

\section{Statistical analyses}

Our analyses tested two hypotheses. The first is that the quality of care provided for NCDs (measured by physicians' $\mathrm{CPV}^{\circ}$ vignette scores) is a function of structural quality measures, physician characteristics, and control variables. We did this because structural inputs, while relatively easy to measure, do not necessarily predict the quality of clinical care or lead to improved outcomes [16]. We estimated $\mathrm{CPV}^{\circ}$ scores as dependent variables, with physician and facility characteristics and control variables for oblast, facility type, and rurality as independent variables.

Quality of care (CPV Score) $=\beta_{0}+\beta_{1}$ Case complexity $+\beta_{2-8}$ Oblast $+\beta_{9}$ Setting $+\beta_{10}$ Facility Level $+\beta_{11-14}$ Facility Infrastructure $+\beta_{15-17}$ MD characteristics $+\beta_{18-19}$ MD training $+\beta_{20-22}$ MD Workload $+\varepsilon$.

COPD and CHF were modeled separately to account for the difference in clinical skills required to care for these two conditions. Generalized estimating equation regression models were used, with corrections to account for clustering of physicians within facilities.

The second hypothesis was that improved quality of care for NCDs was linked to improved health outcomes. We estimated models with GSRH as the dependent variable, quality (measured by $\mathrm{CPV}^{\circ}$ vignette scores, averaged for COPD and $\mathrm{CHF}$ ) as the main independent variable, and patient or household survey respondent characteristics as control variables.

Patient exit survey data were linked to the physician and health facility where each patient was seen. Because it was not possible to ascribe a household respondent to a particular physician, we linked household survey data with the polyclinic(s) serving each household survey EA. Most EAs were served by one polyclinic each, and we used the average of all $\mathrm{CPV}^{\circ}$ vignette scores from that facility. If one polyclinic served two EAs, it was linked to each EA; if two polyclinics served the same EA, we averaged $\mathrm{CPV}^{\bullet}$ vignette scores across both facilities.

Two models were separately fit for exit survey patients or household survey respondents.

Exit Survey: Health Status (GSRH) $=\beta_{0}+\beta_{1}$ CPV score $+\beta_{2-8}$ Oblast $+\beta_{9-15}$ Oblast* $C P V$ interaction $+\beta_{16}$ Facility Level $+\beta_{17}$ Setting $+\beta_{18-24}$ Patient

Characteristics $+\beta_{25}$ Diagnostic Index $+\beta_{26-28}$

Healthcare utilization $+\beta_{29}$ Smoker $+\varepsilon$
Household Survey: Health Status (GSRH) $=\beta_{0}+\beta_{1}$ CPV score $+\beta_{2-8}$ Oblast $+\beta_{9-15}$ Patient Characteristics $+\beta_{16}$ Diagnostic Index $+\beta_{17-18}$ Healthcare utilization $+\beta_{19-20}$ Objective Health Measures $+\beta_{21-23}$ Healthy Behaviors $+\varepsilon$

Ordered logistic regression was used for both models, as general self-reported health status (GSRH) was the dependent variable. The household model also included objective (BMI and waist measurement) measures of health to control for pre-existing conditions that might skew the self-reported measures. The distribution of GSRH results was normalized within each oblast. The exit survey model was corrected to account for clustering of respondents by physician.

All statistical modeling was carried out using STATA v11.2 (StataCorp, College Station, Texas, USA). Approval for data collection and analyses were obtained from the Ukraine Ministry of Health. The Oregon State University Institutional Review Board determined that this study does not require review as human subjects research.

\section{Results}

Physicians scored $47.4 \%$ on the $\mathrm{CPV}^{\bullet}$ vignettes, averaged by complexity and disease type. They had higher scores on CHF (53\%) than COPD (42\%). For both diseases, Physicians scored higher on simple than complex cases, although this difference was attenuated for CHF. The physician score distribution was approximately normal across disease types and complexity. When we examined scores by domain, physicians did the best at taking a history and ordering appropriate laboratory tests; they struggled the most with treatment and management. For example, for the CHF case, only $45.5 \%$ of physicians prescribed an ACE inhibitor and only 27.5\% counseled the patient on weight loss. For the COPD case, albuterol was prescribed only $47 \%$ of the time and steroids $33 \%$ of the time. There were only modest differences between physicians in hospitals versus polyclinics, including diagnostic abilities, although scores were always higher at oblast hospitals (See Table 2).

Regarding our first hypothesis of the effect of facility and physician characteristics on quality, we found that physician-level determinants of higher $\mathrm{CPV}^{\circ}$ vignette scores were age, gender, and relevant continuing medical education (CME)-younger, female physicians and those who had CME in chronic disease or health behaviors in the past year provided higher quality care (Table 4). Specialist physicians performed better on CHF, but not on COPD.

None of the facility-level structural characteristicsequipment, lab test availability, supplies, or number of committees (a proxy for organizational integration)had a significant impact on the quality of care. No 
Table 3 Patient characteristics by exit interviews and household survey respondent characteristics

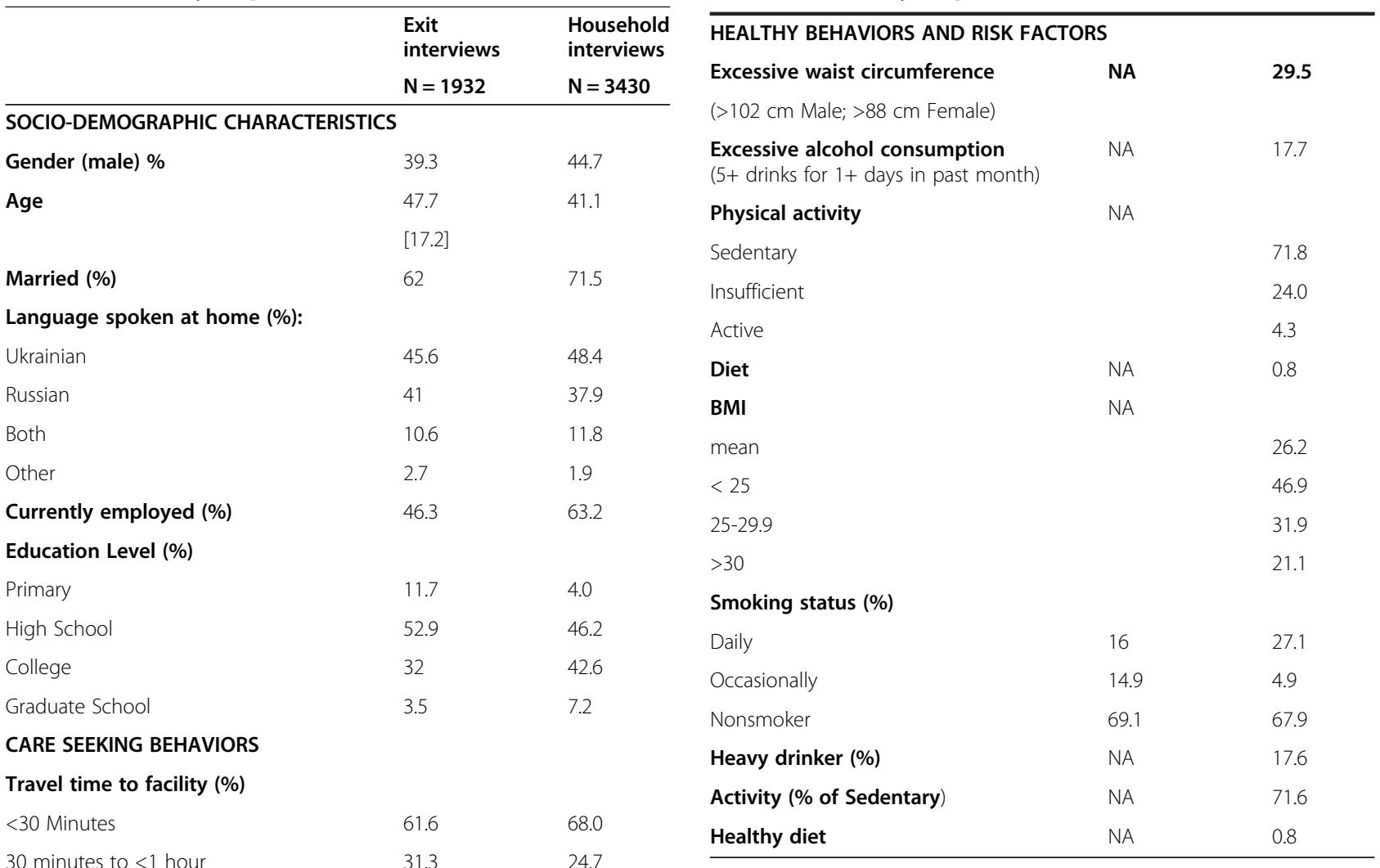

$>4$ hours

Outpatient visits in previous

12 months (mean)

Outpatient visit in past

30 days (\% yes)

Outpatient visits in past

30 days (mean)

HEALTH STATUS INDICATORS

GSRH (\%)

Very Good

Good

Satisfactory

Bad

Very Bad

Number of Chronic Conditions

Hospitalized in previous

12 months (\%)

Average \# of hospitalizations overnight care

Average \# of hospitalizations inpatient day care

Table 3 Patient characteristics by exit interviews and household survey respondent characteristics (Continued)

HEALTHY BEHAVIORS AND RISK FACTORS

xcessive waist circumference

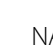

NA

24.7

6.6

0.8

N.A.

significant differences in quality were observed between urban-serving and rural-serving facilities, or between hospitals and polyclinics. There was large regional variation in quality when oblasts were compared to Crimea, which had the lowest $\mathrm{CPV}^{\circ}$ vignette scores. Quality did not vary significantly if physicians worked in other facilities, had a higher proportion of elderly patients, or consistently had a medical record available for patient visits.

Regarding our second hypothesis that higher quality is linked to better outcomes, we found that higher $\mathrm{CPV}^{\circ}$ vignette scores were significantly associated with better GSRH among both exit survey patients (Table 5) and the general adult population (Table 6). Regional variation was more often significant in the household survey model than in the exit survey. Patient or respondent age, gender, current employment, and level of wealth had a significant impact on GSRH in both models. The number of chronic conditions and recent hospitalization were also significant in both models. Facility type and travel time to the nearest facility were available only in the exit survey and were significant. In the household survey model, we included several respondent level variables not available from patient exit survey. Having sought medical assistance within the past 30 days was significantly associated with GSRH, but BMI, waist circumference, and being a heavy 
Table 4 GEE Regression analysis of Quality from $\mathrm{CPV}^{\circledR}$ scores, by case type

\begin{tabular}{|c|c|c|c|c|}
\hline & COPD & & $\mathrm{CHF}$ & \\
\hline & $n=94$ & & $\mathrm{n}=94$ & \\
\hline & Coef & p-value & Coef & $\mathrm{p}$-value \\
\hline Constant & 43.89 & 0.00 & 49.93 & 0.00 \\
\hline CPV Taken is Complex & -1.50 & 0.05 & -0.70 & 0.35 \\
\hline Oblast $=$ Winnitca & 4.33 & 0.03 & 9.98 & 0.00 \\
\hline Oblast = Dnipropetrovs'k & 3.40 & 0.16 & 7.14 & 0.00 \\
\hline Oblast $=$ Kyiv & -0.79 & 0.76 & 4.13 & 0.09 \\
\hline Oblast $=$ Lugansk & 6.25 & 0.00 & 10.06 & 0.00 \\
\hline Oblast $=$ Lviv & 1.89 & 0.40 & 6.12 & 0.01 \\
\hline Oblast $=$ Odessa & 4.08 & 0.05 & 9.56 & 0.00 \\
\hline Oblast $=$ Rivne & 0.50 & 0.84 & 5.44 & 0.02 \\
\hline Urban & -0.05 & 0.97 & 1.15 & 0.26 \\
\hline Hospital & 0.60 & 0.59 & 0.30 & 0.80 \\
\hline Equipment index & 0.02 & 0.48 & -0.02 & 0.55 \\
\hline Lab index & -0.01 & 0.65 & -0.01 & 0.58 \\
\hline Supply index & 0.02 & 0.49 & 0.03 & 0.33 \\
\hline Number of Committees & -0.40 & 0.21 & 0.17 & 0.58 \\
\hline Age of MD & -0.15 & 0.00 & -0.14 & 0.00 \\
\hline MD is Male & -2.22 & 0.03 & -2.76 & 0.00 \\
\hline MD Speaks only Russian & -1.31 & 0.27 & -2.06 & 0.05 \\
\hline MD is generalist & -2.23 & 0.18 & -2.80 & 0.05 \\
\hline With CME at least 3 years age that lasted at least two days & 2.38 & 0.01 & 2.22 & 0.02 \\
\hline Prop of MD patient age 55 and above & 0.04 & 0.11 & 0.03 & 0.18 \\
\hline MD works in other facility & -0.81 & 0.61 & -1.68 & 0.21 \\
\hline W/ record for at least $75 \%$ of patients & 0.73 & 0.45 & 1.12 & 0.22 \\
\hline
\end{tabular}

Analysis takes into account clustering by facility.

drinker were not. Smoking and marital status were not significantly associated with GSRH in either model.

\section{Discussion}

Ukraine's ongoing mortality crisis is driven by the high prevalence and inadequate treatment of NCDs [26,27]. A growing body of international evidence suggests that improved quality of care can significantly improve the diagnosis and treatment of such diseases, and thereby improve population health outcomes [28]. This study therefore measured the quality of care for two NCDs with a high burden of disease in Ukraine, and addressed two important questions for health policy:

1. How do health care facility and physician characteristics impact quality?

2. Does quality impact the health of clinic patients and/or the general population served by these clinics?

This study used a previously validated method-Clinical Performance and Value $\left(\mathrm{CPV}^{\circ}\right)$ vignettes-to measure the quality of care for COPD and CHF. Quality was measured at a large number of primary care sites and hospital outpatient clinics across Ukraine, sampled based upon a prior household survey. At the study facilities, additional surveys measured facility and physician characteristics that might impact quality. Patients seen by physicians completing $\mathrm{CPV}^{\circ}$ vignettes were asked to complete exit surveys, and the household survey provided health data about the general adult population.

Overall, the quality of care for COPD and CHF in Ukraine is substandard, with average scores of $47.4 \%$ being below the $50-60 \%$ range typically observed in other countries [29] or the average scores of $60.2-62.6 \%$ reported for communicable and perinatal conditions in a five-country study [16]. Scores in Ukraine are comparable to the $47.7-48.4 \%$ range seen in Macedonia, another Eastern European setting [7], but well below those of $65 \%$ for COPD and $70 \%$ for vascular disease observed in the United States [14]. Other investigators have also found COPD care in Ukraine to be of poor quality [30]. Consistent with $\mathrm{CPV}^{\circ}$ results from other countries, we 
Table $\mathbf{5}$ Impact of quality on self-reported health status using general self-reported health status: exit survey

\begin{tabular}{|c|c|c|}
\hline & \multicolumn{2}{|l|}{ Exit survey } \\
\hline & \multicolumn{2}{|l|}{$\mathrm{N}=1762$} \\
\hline & Odds ratio & p-value \\
\hline Actual CPV score (Average of COPD \& CHF) & 1.03 & 0.04 \\
\hline Oblast $=$ Winnitca & 2.02 & 0.61 \\
\hline Oblast = Dnipropetrovs'k & 2.33 & 0.29 \\
\hline Oblast $=$ Kyiv & 1.66 & 0.57 \\
\hline Oblast = Lugansk & 2.13 & 0.39 \\
\hline Oblast $=$ Lviv & 2.73 & 0.33 \\
\hline Oblast $=$ Odessa & 1.62 & 0.60 \\
\hline Oblast $=$ Rivne & 0.71 & 0.73 \\
\hline $\mathrm{CPV}^{*}$ Oblast $=$ Winnitca & 0.97 & 0.22 \\
\hline $\mathrm{CPV}^{*} \mathrm{Oblast}=$ Dnipropetrovs ${ }^{\prime} \mathrm{k}$ & 0.95 & 0.00 \\
\hline $\mathrm{CPV}^{*}$ Oblast $=$ Kyiv & 0.99 & 0.48 \\
\hline $\mathrm{CPV}^{*}$ Oblast $=$ Lugansk & 0.97 & 0.12 \\
\hline $\mathrm{CPV}^{*}$ Oblast $=$ Lviv & 0.97 & 0.12 \\
\hline $\mathrm{CPV}^{*}$ Oblast $=$ Odessa & 0.99 & 0.45 \\
\hline$C P V^{*}$ Oblast $=$ Rivne & 0.97 & 0.18 \\
\hline Hospital & 0.63 & 0.01 \\
\hline Urban & 0.87 & 0.34 \\
\hline Patient's age & 0.97 & 0.00 \\
\hline Patient is male & 1.53 & 0.00 \\
\hline Patient is married & 1.02 & 0.86 \\
\hline Patient speaks mainly Russian & 1.02 & 0.85 \\
\hline Employed & 1.27 & 0.04 \\
\hline Years of schooling & 1.09 & 0.00 \\
\hline Asset index & 0.53 & 0.00 \\
\hline Diagnosis index ${ }^{\ddagger}$ & 0.66 & 0.00 \\
\hline 2 & 0.48 & 0.00 \\
\hline 3 & 0.37 & 0.00 \\
\hline $4+$ & 0.28 & 0.00 \\
\hline With hospitalization & 0.55 & 0.00 \\
\hline Travel time $=$ at least one hour & 0.69 & 0.05 \\
\hline Patient is smoker & 0.92 & 0.47 \\
\hline
\end{tabular}

Ordered logit accounting for clustering at the physician level. Oblast and $\mathrm{CPV}^{*}$ Oblast comparator $=$ Crimea; ${ }^{\ddagger}$ Number of chronic diseases, comparator $=0-1$ diseases

observed wide variation across providers within Ukraine, with many scores of 65 and above, particularly at oblast hospitals.

At the facility level, structural characteristics did not predict quality scores, a finding consistent with other studies [9]. There were also not significant differences in quality between urban- and rural-serving facilities, or between hospitals and polyclinics. There was, however, significant regional variation in quality across oblasts.
Table 6 Impact of quality on self-reported health status using general self-reported health status: household survey

\begin{tabular}{|c|c|c|}
\hline & Household & \\
\hline & $\mathrm{N}=2844$ & \\
\hline & Odds ratio & p-value \\
\hline $\begin{array}{l}\text { Average CPV score } \\
\text { (average of CPVs at the facility level) }\end{array}$ & 1.02 & 0.05 \\
\hline By region: & & \\
\hline Oblast $=$ Winnitca & 1.97 & 0.00 \\
\hline Oblast = Dnipropetrovs'k & 4.04 & 0.00 \\
\hline Oblast $=$ Kyiv & 2.65 & 0.00 \\
\hline Oblast = Lugansk & 1.44 & 0.05 \\
\hline Oblast $=$ Lviv & 1.34 & 0.12 \\
\hline Oblast $=$ Odessa & 0.82 & 0.24 \\
\hline Oblast = Rivne & 1.49 & 0.02 \\
\hline Age & 0.96 & 0.00 \\
\hline Male & 1.45 & 0.00 \\
\hline Married & 0.94 & 0.44 \\
\hline Speaks mainly Russian & 0.99 & 0.93 \\
\hline Employed & 1.37 & 0.00 \\
\hline Educ $=$ Primary Level & 0.74 & 0.10 \\
\hline Lowest wealth quintile & 0.76 & 0.00 \\
\hline Number of chronic conditions & 0.43 & 0.00 \\
\hline W/ medical assistance in past 30 days & 0.47 & 0.00 \\
\hline With hospitalization & 0.46 & 0.00 \\
\hline BMl & 0.99 & 0.78 \\
\hline Waist risk & 0.85 & 0.12 \\
\hline Smokes & 0.90 & 0.25 \\
\hline Heavy drinker & 0.91 & 0.33 \\
\hline Sufficient physical activity & 0.82 & 0.26 \\
\hline
\end{tabular}

Oblast and $\mathrm{CPV}^{*}$ Oblast comparator $=$ Crimea.

At the physician level, recent continuing medical education had a positive impact on the quality of care provided. Similar to results from other countries, younger and female physicians had higher scores, but other physician characteristics were associated with quality levels. Interestingly, working at another facility did not impact quality.

At the patient and population level, higher quality was associated with better health status, controlling for age, education, employment, and wealth. Specifically, higher physician $\mathrm{CPV}^{\star}$ vignettes cores were associated with better GSRH among clinic patients, and higher scores at facilities were positively associated with GSRH among adults in neighborhoods served by those facilities. As expected, younger age, less chronic illness, and lower prior utilization of health care were associated with better health status. Somewhat surprisingly, health behaviors or 
objective health measures had a very limited impact on health status after controlling for other factors.

These findings have several implications for health policy in Ukraine and other LMICs. Most important, higher quality of care can mitigate some of the more intransigent socioeconomic determinants of health, making quality improvement an important policy goal to overcome inequities in both service provision and disease burden. The low treatment domain scores we observed, coupled with the widely demonstrated impact of inexpensive secondary prevention on improving health outcomes for NCDs such as CAD, CHF, and COPD [31], suggest that improved quality of care is a practical objective for health policy.

Specifically, health system investments and payment reforms can emphasize improvements in clinical practice. Expansion of primary care increases the pool of new physicians trained in treating NCDs [32], and CME can improve such skills among the existing physician workforce. Payment mechanisms can also encourage the provision of NCD care that meets international standards. For example, when quality is measured and the results fed back to physicians, incentives and interventions have been shown to lead to rapid improvements in clinical practice and patient outcomes [22,33].

The non-significant effect of structural measures indicates that policies directly targeting clinical practice can operate independent of investments in new or renovated facilities. This does not suggest foregoing investments in equipment and supplies, but instead highlights that material inputs are not necessarily dominant over actual clinical practice.

Finally, our results point out the need to target policies on a regional basis. The regional variation observed in Ukraine was greater than the rural-urban quality differential seen in other countries. Therefore, even though nearly all physicians could benefit from, for example, additional CME in COPD and CHF, analyses such as those presented here can be used to better inform targeting additional resources to regions with lower $\mathrm{CPV}^{\circ}$ scores.

There are limitations to this study. Its main health outcome is self-reported health status; ideally this measure is also accompanied by objective health measures, which for budgetary reasons was not possible for exit survey patients. Exit survey patients were not initially screened for COPD or CHF, and may not be fully representative of Ukraine residents with those conditions. Future studies would gain power by stratifying patients by the diseases of interest. For the household survey, we are not able to confirm that respondents attended the sampled facilities, even though households were linked to facilities by enumeration area. If physicians who refused to participate would have had lower $\mathrm{CPV}^{\circ}$ scores than participating physicians, the actual quality of care provided may be even lower than estimated in this study. Finally, debate continues on whether vignettes measure knowledge or practice. The $\mathrm{CPV}^{\circ}$ vignettes are explicitly structured to address this concern, and validation studies have been designed and implemented in a number of settings showing that $\mathrm{CPV}^{\circ}$ vignettes do measure practice [14]. Perhaps most importantly, this study provides only a snapshot at one point in time. Policy efforts would greatly benefit from evaluating the impact of different approaches on the quality of care and population health.

\section{Conclusions}

As LMICs face a growing burden of non-communicable diseases, addressing the quality of care will be an important policy priority. This study's evidence of linkage between quality and health status suggests that policy makers should strongly consider approaches that directly aim to improve the quality of care health services and thereby enhance population health.

\section{Competing interests}

The authors declare that they have no competing interests.

\section{Authors' contributions}

JWP, RM and JL designed the study and instruments. JL oversaw the study implementation. JL, LD and JWP carried out the data analysis. All authors participated in drafting the manuscript. All authors reviewed and approved the final manuscript.

\section{Acknowledgments}

Funding for this study was provided by the World Bank in cooperation with the Ukrainian Medical Association. We acknowledge the support of the Oleksandr Razumkov Ukrainian Centre for Economic and Political Research in data collection. We would like to thank Jhiedon Florentino for his help on data analysis, Jenifer Marie Tiu for her help in managing the scoring process of the CPV ${ }^{\circledR}$ vignettes, and Iryna Postolovska for assistance in creating and refining datasets for analysis.

\section{Author details}

${ }^{1}$ QURE Healthcare, 1000 Fourth Street, Ste 300, San Rafael, CA 94901, USA. ${ }^{2}$ University of California, 50 Beale Street, 12th Floor, San Francisco, CA 94105, USA. ${ }^{3}$ College of Public Health and Human Sciences, Oregon State University, 401 Waldo Hall, Corvallis, OR, USA. ${ }^{4}$ Tanzania, Uganda and Burundi, Human Development Sector Unit, Africa Region, The World Bank, Room 410, 50 Mirambo Street, P. O. Box 2054, Dar Es Salaam, Tanzania.

Received: 7 March 2014 Accepted: 11 September 2014 Published: 30 September 2014

\section{References}

1. World Bank: What Underlies Ukraine's Mortality Crisis? Washington DC: The World Bank; 2010. [Accessed 14 March 2013]; Available at: http:// siteresources.worldbank.org/UKRAINEINUKRAINIANEXTN/Resources/ PrichinysmertnostivukrainiENG.E.pdf

2. Mackenbach JP, Murphy A, McKee M: Ukraine: not only a matter of geopolitics. Lancet 2014, 383:848-850.

3. World Health Organization: World Health Statistics 2011. Geneva: World Health Organization; 2011.

4. WHO Regional Office for Europe: The European Health Report 2002 Copenhagen: WHO Regional Publications; 2002. European Series, No. 97 [Accessed 15 March 2013]. Available at: http://www.euro.who.int/en/ publications/abstracts/european-health-report-2002-the.

5. Council NR: Promoting cardiovascular health in the developing world: a critical challenge to achieve global health. Washington DC: The National Academies Press; 2010. 
6. OECD: Improving Value in Health Care: Measuring Quality. Paris: Organization for Economic Co-operation and Development; 2010:2010.

7. Das J, Holla A, Das V, Mohanan M, Tabak D, Chan B: In urban and rural India, a standardized patient study showed low levels of provider training and huge quality gaps. Health Aff 2012, 31(12):2774-2784.

8. Das J: The quality of medical care in low-income countries: from providers to Markets. PLoS Med 2011, 8(4):e1000432.

9. Peabody JP, Nordyke RJ, Tozija F, Luck J, Muñoz J, Suderland A, DeSalvo K, Ponce N, McCulloch C: Quality of care and its impact on population health: a cross-sectional study in Macedonia. Soc Sci Med 2007, 62:2216-2224

10. Lekhan $V$, Rudiy $V$, Richardson E: Ukraine: Health system review. Health Syst Transit 2010, 12:1-183.

11. Luck J, Peabody JW, DeMaria LM, Alvarado CS, Menon R: Patient and Provider Perspectives on quality and health system effectiveness in a transition economy: Evidence from Ukraine. Soc Sci Med 2014, 114:57-67.

12. Danyliv A, Pavlova M, Gryga I, Groot W: Willingness to pay for physician services at a primary contact in Ukraine: results of a contingent valuation study. BMC Health Serv Res 2013, 13:208.

13. Peabody J, Luck J, Glassman P, Dresselhaus T, Lee M: Comparison of vignettes, standardized patients, and chart abstraction: a prospective validation study of 3 methods for measuring quality. JAMA 2000, 283(13):1715-1722.

14. Peabody J, Luck J, Glassman P, Jain S, Hansen J, Spell M, Lee M: Measuring the quality of physician practice by using clinical vignettes: a prospective validation study. Ann Intern Med 2004, 141(10):771-780.

15. Fukuhara S, Nishimura M, Nordyke RJ, Zaher CA, Peabody JW: Patterns of care for COPD by Japanese physicians. Respirology 2005, 10(3):341-348.

16. Peabody JP, Liu A: A cross-national comparison of the quality of clinical care using vignettes. Health Policy Plan 2007, 22:294-302

17. Butrick E, Peabody JW, Solon O, DeSalvo KB, Quimbo SA: A comparison of objective biomarkers with a subjective health status measure among children in the Philippines. Asia-Pac J Public He 2010, 24(4):565-576.

18. DeSalvo KB, Bloser N, Reynolds K, He J, Munter P: Mortality prediction with a single general self-rated health question: a meta-analysis. $J$ Gen Intern Med 2006, 21(3):267-275.

19. Kawada T: Self-rated health and life prognosis. Arch Med Res 2003, 34:343-347.

20. DeSalvo KB, Jones TM, Peabody JW, McDonald J, Fihn S, Fan V, He J, Munter P: Health care expenditure prediction with a single item, self-rated measure. Med Care 2009, 47(4):440-447.

21. DeSalvo KB, Fan VS, McDonell MD, Fihn SD: Predicting mortality and healthcare utilization with one question. Health Serv Res 2005, 40(4):1234-1236.

22. Peabody JW, Shimkhada R, Quimbo S, Florentino J, Bacate MF, McCulloch C, Solon O: Financial incentives and measurement improved physicians" Quality of care in the Philippines. Health Aff 2011, 10(4):773-781.

23. Global Initiative for Chronic Obstructive Lung Disease: Global Strategy for the Diagnosis, Management and Prevention of COPD, Global Initiative for Chronic Obstructive Lung Disease (GOLD). In 2011. [Accessed 05 March 2013] Available at: http://www.goldcopd.org.

24. Hunt SA, Baker DW, Chin MH, Cinquegrani MP, Feldman AM, Francis GS, Ganiats TG, Goldstein S, Gregoratos G, Jessup ML, Noble RJ, Packer M, Silver MA, Stevenson LW, Gibbons RJ, Antman EM, Alpert JS, Faxon DP, Fuster V, Gregoratos G, Jacobs AK, Hiratzka LF, Russell RO, Smith SC Jr, American College of Cardiology/American Heart Association Task Force on Practice Guidelines (Committee to Revise the 1995 Guidelines for the Evaluation and Management of Heart Failure); International Society for Heart and Lung Transplantation; Heart Failure Society of America: ACC/AHA Guidelines for the evaluation and management of chronic heart failure in the adult: executive summary. A report of the American College of Cardiology/ American Heart Association Task Force on Practice Guidelines (Committee to Revise the 1995 Guidelines for the Evaluation and Management of Heart Failure): developed in collaboration with the International Society for Heart and Lung Transplantation; endorsed by the Heart Failure Society of America. Circulation 2001, 104:2996-3007.

25. Balkrishnan R, Anderson RT: Self-reported health status predictors of healthcare services utilization and charges in elderly asthmatic patients. J Asthma 2000, 37(5):415-423.
26. Abegunde DO, Mathers CD, Adam T, Ortegon M, Strong $K$ : The burden and costs of chronic diseases in low-income and middle-income countries. Lancet Dec 2007, 8(9603):1929-1938.

27. Lekhan V, Rudiy V, Nolte E: Health Care Systems in transition (HiT). Ukraine. Copenhagen: WHO Regional Office for Europe on behalf of the European Observatory on Health Systems and Policies; 2004.

28. Derose SF, Petitti DB: Measuring quality of care and performance from a population health care perspective. Annu Rev Public Health 2003, 24:363-384

29. Das J, Hammer J: Which Doctor? Combining Vignettes and Item Response to Measure Doctor Quality. Washington DC: World Bank; 2004. Policy Research Working Paper Series No.: 3301.

30. Vyshnyvetskyy I, Khitrenko O, Kugler T: Quality of care of acute exacerbations of COPD and asthma in adults: a phone survey in Ukraine. Chest 2012, 142(4_MeetingAbstracts):418A.

31. Beaglehole R, Epping-Jordan J, Patel V, Chopra M, Ebrahim S, Kidd M, Haines $A$ : Improving the prevention and management of chronic disease in low-income and middle-income countries: a priority for primary health care. Lancet 2008, 372(9642):940-949.

32. Kolesnyk P, Svab I: Development of family medicine in Ukraine. Eur J Gen Prac 2013, 19(4):261-265.

33. Peabody JW, Shimkhada S, Quimbo S, Solon O, Javier X, McCulloch C: The impact of performance incentives on health outcomes: results from a cluster randomized controlled trial in the Philippines. Health Policy Plan 2013, 29:1-7.

\section{doi:10.1186/1472-6963-14-446}

Cite this article as: Peabody et al:: Quality of care and health status in Ukraine. BMC Health Services Research 2014 14:446.

\section{Submit your next manuscript to BioMed Central and take full advantage of:}

- Convenient online submission

- Thorough peer review

- No space constraints or color figure charges

- Immediate publication on acceptance

- Inclusion in PubMed, CAS, Scopus and Google Scholar

- Research which is freely available for redistribution

Submit your manuscript at www.biomedcentral.com/submit
C) Biomed Central 